\title{
Addressing Psychosocial Care Using an Interactive Web site for Combat-Wounded Patients
}

\author{
Reg Arthur Williams, PhD, RN, BC, FAAN, Gary Gatien, MA, Bonnie M. Hagerty, PhD, RN, \\ Michele Kane, PhD, RN, Laureen Otto, PhD, RN, Candy Wilson, PhD, APRN, and Meryia Throop, PhD, RN \\ Reg Arthur Williams, PhD, RN, BC, FAAN, is Professor, School of Nursing and Psychiatry, Medical School, University of Michigan, Ann Arbor, MI, USA; \\ Gary Gatien, MA, is Project Manager, School of Nursing, University of Michigan, Ann Arbor, MI, USA; Bonnie M. Hagerty, PhD, RN, is Associate \\ Professor and Associate Dean of Undergraduate Studies, School of Nursing, University of Michigan, Ann Arbor, MI, USA; Michele Kane, PhD, RN, is \\ Commander, NC, USN, Walter Reed National Military Medical Center, Bethesda, MD, USA; Laureen Otto, PhD, RN, is Major, Army Nurse Corps, Brooke \\ Army Medical Center, San Antonio, TX, USA; Candy Wilson, PhD, APRN, is Lieutenant Colonel, Air Force Nurse Corps, Wilford Hall Medical Center, \\ San Antonio, TX, USA; and Meryia Throop, PhD, RN, is MAJ, Army Nurse Corps, Walter Reed National Military Medical Center, Bethesda, MD, USA
}

Search terms:

Combat, depression, military nurses, psychosocial, PTSD, stress

\author{
Author contact: \\ rawill@umich.edu, with a copy to the Editor: \\ gpearson@uchc.edu
}

Conflict of Interest Statement

The authors reported no conflict of interest.

First Received November 15, 2011; Final Revision received February 29, 2012; Accepted for publication April 4, 2012.

doi: 10.1111/j.1744-6163.2012.00344.x
PURPOSE: The aims were to examine military nurses and combat-wounded patients' evaluation of a cognitive behavioral intervention Web site called Stress Gym. DESIGN AND METHODS: The use of the intervention was a proof-of-concept design with 129 military nurses and combat-wounded patients in military medical treatment facilities (MTFs). The nurses and patients logged on to Stress Gym, reviewed the nine modules available, and completed a short evaluation of the Web site. FINDINGS: The evaluation of the military nurses and patients was high. There were no significant differences in the evaluation based on military services, sex, deployment, and education levels.

PRACTICE IMPLICATIONS: The strength of Stress Gym is that it enables all military members to learn about and get help with problems such as stress, anxiety, anger, and depressive symptoms anonymously and in private.

CLINICAL RELEVANCE: Stress Gym is a versatile tool that can help nurses address the psychosocial needs of their patients by encouraging its use and including it in treatment protocols.
Stress Gym was developed as a first-level, evidence-based, Web site intervention to help U.S. military members learn how to manage mild to moderate stress and depressive symptoms using a self-help intervention with progress tracking and 24/7 availability. It was designed using Web-based, health management intervention design elements that have been proven effective and users have reported they prefer. These included interactivity, self-pacing, and pleasing aesthetics (Williams, Hagerty, Brasington, Clem, \& Williams, 2010). Stress Gym was adapted for this study for combat-wounded patients as military nurses are fighting their own battles to manage the number of combat casualties from Operation Iraqi Freedom and Operation Enduring Freedom. Service members' psychosocial needs for support to manage their stress and combat injuries are immense. Military nurses who treat combat-wounded patients evaluated the tailored intervention to make recommendations of its utility and effectiveness for their patients. The patients evaluated Stress Gym for a variety of factors, including utility and ease of use.

Therefore, the specific aims of the study were to examine nurses' recommendation of Stress Gym for combat-wounded patients in the Navy, Air Force, and Army military medical treatment facilities (MTFs), and evaluate the patients' ease of use, understanding, content, formatting, and motivation and intent to use the intervention. A second specific aim was to examine the combat-wounded patients' evaluation of Stress Gym, but there were insufficient numbers that participated in the study. Only a brief description of their participation can be made.

\section{Background and Significance}

E-Learning, the use of a Web site for education without the use of a live facilitator, has become a popular method for educating the lay public, offering classes for credit, for continuing education online, and for training employees for new job skills. Numerous Web sites exist, which purport interactive preprogrammed advice, and some send tailored health messages to patients.

Despite e-Learning's intrigue and promise as a low costmedium for education, user behavioral problems plague its widespread use. The users of e-Learning complain of it being 
boring (Prescott, 2001). Completion rates for e-Learning courses are commonly under 30\% (Flood, 2002), and the challenge for Web site e-Learning designers is how to keep users at a Web site long enough to learn the content.

Internet technology provides new opportunities for delivering psychological interventions. Through the Internet, providers can deliver tailored interventions to a large number of participants in a cost-effective manner. This method can also preserve anonymity, an important aspect for military personnel who want to keep their psychiatric and stress concerns private, thus avoiding perceived damage to their military career. While there is some published information about delivering health interventions via the Internet, the number of studies using this technology is small. In addition, studies that have been done are usually focused on illnesses such as cancer. Christensen, Griffiths, and Korten (2002) called for better-designed research projects regarding the effectiveness of Internet interventions.

In the realm of mental health, the few well-designed studies that examine the use of the Web to deliver mental health interventions have provided some promising results based on the small number of studies that have been done. Several authors such as Christensen et al. (2002) and Clarke et al. (2002) described their development of a Web-based, cognitivebehavioral intervention designed to prevent depression and anxiety. As participants completed study modules over 6 months, depression and anxiety symptoms decreased significantly. However, Clarke and colleagues found that those participants with low levels of depressive symptoms at the time of intake took advantage of the Web intervention and improved, whereas those who were severely depressed did not use the Internet.

Other studies have focused on Web-based interventions for patient populations other than those with stress, anxiety, and depression. Lieberman et al. (2003) and Winzelberg et al. (2003) provided Internet support groups to women with breast cancer. There was a significant decrease in depression and reactions to pain, which included a significant decrease in cancer trauma, and perceived stress as well as high participant satisfaction. In a study investigating the effects of an Internet intervention for persons with AIDS, Flatley-Brennan (1998) found that the use of the intervention was successful in decreasing social isolation only after the depressive symptoms had decreased. These findings are congruent with those by Clarke et al. (2002), in which those participants with more depressive symptoms were less likely to use the Internet intervention. Thus, delivering Internet interventions has multiple advantages, but additional research is required to examine the context, timing, and covariates that affect success of such an intervention.

Unique to Stress Gym were the practical strategies that helped sailors manage the stresses of military service (Williams et al., 2010). This feasibility study preceded Stress Gym for Combat-Wounded Patients, which tested Stress Gym for Web-based learning and helped to identify the feasibility of using this modality to augment standard care for the Navy sailors. Stress Gym for Combat-Wounded Patients was developed using the model of cognitive appraisal of Lazarus and Folkman (1984) and the series of studies on stress and depression in military members (Williams, Hagerty, Yousha, Hoyle, \& Oe, 2002; Williams et al., 2004, 2007, 2010).

\section{Methods}

The use of the intervention was a proof-of-concept design to examine nurses' recommendation for combat-wounded patients in the Navy, Air Force, and Army MTFs. Stress Gym was also evaluated by combat-wounded patients to address their emotional needs because of war injuries.

\section{Sample}

There were 124 nurses who participated in the study. The sample comprised 14.5\% (18) nurses from Brooke Army Medical Center, San Antonio, Texas; 52.4\% (65) from National Naval Medical Center, Bethesda, Maryland; 21\% (26) from Wilford Hall Medical Center, San Antonio, Texas; and $12.1 \%$ (15) from Walter Reed Army Medical Center, Bethesda, Maryland. The participants comprised 61\% (72) active duty, 5.9\% (7) reservists, $24.6 \%$ (29) government service (GS) employees, 8.5 (10) contract nurses, and six nurses did not indicate their service status. The active duty and reserve nurses ranged in rank from Second Lieutenant/ Ensign (O-1) to Colonel/Captain (O-6), and the GS nurses ranged from GS-7 to GS-12. There was a significant difference in the number of men participating in the Army MTFs as compared with the Navy and Air Force. In addition, there was a slight significant difference in the racial/ethnic background characteristics of the four MTFs. However, there were no significant differences in age, mean number of years working as a nurse, mean number of years in the military, and mean number of deployments made by the military nurses. There were 50 nurses who reported previous deployment, with $24.2 \%$ being deployed once, $11.3 \%$ twice, and 4.8 three or more times (Table 1).

The largest percent of specializations of the nurses were medical/surgical 34.2\% $(n=40)$, intensive care units $20.5 \%$ ( $n$ $=24)$, and operating room/perioperative $12.8 \%(n=15)$. The remaining $32.5 \%(n=45)$ were in such specialty nursing areas as oncology, cardiology, and psychiatry.

There were only five patients who participated in the study, which limited the analysis. One patient did not answer all the demographic questions; therefore, the mean age of the four patients was 35.3 ( $S D=17.2$; ranged from 24 to 42 ) and they had been in the military service an average of 14.5 years $(S D=$ 6.7). There were three male and two female patients; one 
Table 1. Demographic and Background Characteristics of the Nurses $(n=124)$

\begin{tabular}{|c|c|c|c|c|c|}
\hline Variables & BAMC & NNMC & WHMC & WRAMC & Test \\
\hline \multicolumn{6}{|l|}{ Sex \% $(n)$} \\
\hline Male & $38.9(7)$ & $16.9(11)$ & $28.0(7)$ & $57.1(8)$ & \multirow[t]{2}{*}{$\chi^{2}(3)=11.1, p=.011$} \\
\hline Female & $61.1(11)$ & $83.1(54)$ & $72.0(18)$ & $42.9(6)$ & \\
\hline \multicolumn{6}{|l|}{ Education \% (n) } \\
\hline Some college & $5.9(1)$ & $1.6(1)$ & $0.0(0)$ & $7.7(1)$ & \multirow[t]{5}{*}{$\chi^{2}(4)=164.6, p=$ NS } \\
\hline Associate degree & $11.8(2)$ & $4.8(3)$ & $4.3(1)$ & $0.0(0)$ & \\
\hline Bachelor's degree & $47.1(8)$ & $54.0(34)$ & $43.5(10)$ & $76.9(10)$ & \\
\hline Master's degree & $29.4(5)$ & $38.1(24)$ & $47.8(11)$ & $15.4(2)$ & \\
\hline Doctorate & $5.9(1)$ & $1.6(1)$ & $4.3(1)$ & $0.0(0)$ & \\
\hline \multicolumn{6}{|l|}{ Ethnic/race \% (n) } \\
\hline African American & $11.1(2)$ & $11.1(7)$ & $4.5(1)$ & $42.9(6)$ & \multirow[t]{5}{*}{$\chi^{2}(4)=25.1, p=.014$} \\
\hline Asian American & $0.0(0)$ & $6.3(4)$ & $18.2(4)$ & $7.1(1)$ & \\
\hline White & $72.2(13)$ & $77.8(49)$ & $72.7(16)$ & $42.9(6)$ & \\
\hline Hispanic & $16.7(3)$ & $1.6(1)$ & $4.5(1)$ & $7.1(1)$ & \\
\hline Other & $0.0(0)$ & $3.2(2)$ & $0.0(1)$ & $0.0(0)$ & \\
\hline Age mean $(S D)$ & $36.4(10.9)$ & $39.3(13.1)$ & $36.2(12.7)$ & $42.9(11.3)$ & $F(3,119)=1.1, p=N S$ \\
\hline Mean years as a nurse & $10.1(10.5)$ & $16.6(10.8)$ & $13.6(7.2)$ & $11.7(13.1)$ & $F(3,110)=2.3, p=N S$ \\
\hline Mean years in the military & $11.2(9.3)$ & $15.1(9.0)$ & $13.6(6.2)$ & $10.7(7.4)$ & $F(3,83)=1.4, p=N S$ \\
\hline Mean number of deployments & $1.1(1.9)$ & $0.6(1.2)$ & $0.9(0.88)$ & $0.27(0.46)$ & $F(3,120)=2.4, p=N S$ \\
\hline
\end{tabular}

BAMC, Brooke Army Medical Center; NNMC, National Naval Medical Center, NS, not significant; WHMC, Wilford Hall Medical Center; WRAMC, Walter Reed Army Medical Center.

patient was single and two were married. Their ethnic/racial background was African American (1), Caucasian (1), and other (2). Four were in the U.S. Army, and one was from the Marine Corps with three officers (rank Captain to Major; $\mathrm{O}-3, \mathrm{O}-4)$ and one enlisted (E-4). One patient had completed some college and the others had completed college.

\section{Intervention}

Stress Gym's design was best suited for combat-wounded patients who experienced mild depressive or anxiety symptoms or early stress symptoms (Williams et al., 2004, 2007). If they were having more serious symptoms, then patients could click on an icon on the home page that led them to resources where they could get immediate mental health assistance in their respective Navy, Army, and Air Force services. This icon also appeared on selected Web pages throughout Stress Gym. The modules were written at the 8 th grade level for readability.

Assuming that no immediate mental health assistance was needed, patients could elect to complete any or all of the Stress Gym program modules, described in Table 2. Clicking on any module in the navigation bar would take the patients to the beginning of that module. Module navigation was done by scrolling or clicking through simple interactive Web pages. Users had the option of selecting information and watching animations, opportunities such as writing responses, or graphing their stress levels. Their responses were saved and were accessible each time they accessed the program. Upon completing any or all of the modules, participants were encouraged to complete the Evaluation Questionnaire and then log off. Using their self-generated code, they were able to access the program and their responses at any time in the future.

\section{Instruments}

\section{Nurse Measures}

Nurse's Evaluation Questionnaire. This questionnaire examined nurses' recommendation of Stress Gym for combatwounded patients in the Navy, Air Force, and Army military MTFs, and their evaluation of the patients' ease of use, understanding, content, formatting, and motivation and intent to use the intervention. The first section comprised a five-point, Likert-type scale (strongly agree to strongly disagree) of statements regarding their experience using Stress Gym. Examples are: "Stress Gym covers topics important to combat wounded patients" and "I would recommend Stress Gym to combat wounded patients." In this study, the Cronbach's coefficient alpha reliability of the overall Evaluation Questionnaire 22 -item scale was .97 and the subscales were .83 for Ease of Use; .94 for Understanding; .87 for Content; .88 for Format; .74 for Motivation; and .89 for Intent to Use the Intervention. The second section allowed nurses to write comments on the Web-based intervention, what they liked, disliked, and recommendations for modifications. The final section included demographic information: sex, age, marital status, racial/ ethnic background.The questionnaire also included background questions, such as nurses' rank in the military, years in 
Table 2. Overview of the Modules in Stress Gym for Combat-Wounded Patients

\begin{tabular}{|c|c|}
\hline Stress and emotion & $\begin{array}{l}\text { Individuals are given an overview of the Stress Gym and are introduced to recording their emotionality and stress levels using } \\
\text { a graphing system. }\end{array}$ \\
\hline Reacting to stress & $\begin{array}{l}\text { Specific strategies of stress reduction are described and users learn how they can implement these strategies. These include } \\
\text { such strategies as deep breathing, counting, creating a picture or visualization, and using memory reminders such as } \\
\text { "negative thoughts are energy burners and positive thoughts are energy earners" (Asarnow, Jaycox, \& Thompson, 2001; } \\
\text { Clarke et al., 2002). }\end{array}$ \\
\hline Anger & $\begin{array}{l}\text { In the focus groups (Hagerty et al., 2010), various manifestations of anger surfaced among combat casualty patients. In } \\
\text { response, the module was created to address issues of anger, including Expressions of Anger, Triggers and Coping, and } \\
\text { Alcohol Use. }\end{array}$ \\
\hline Change your thinking & $\begin{array}{l}\text { Users examine distorted thinking. They review examples of distorted thinking such as ignoring the positive and focusing on } \\
\text { the negatives, either-or thinking, overgeneralization, perceiving that others are more successful, "should" statements, and } \\
\text { labeling. This module identifies symptoms of depression and how the brain works with negative thoughts (Beck, Rush, } \\
\text { Shaw, \& Emery, 1979; Kelly, Uddin, Biswal, Castelanos, \& Milham, 2008). The module also explains how selective serotonin } \\
\text { uptake inhibitors help treat depression and what to do if they experience suicidal thoughts. This module also provides } \\
\text { information about post-traumatic stress disorder (PTSD) by an engaging game of PTSD Jeopardy. Patients do not want to } \\
\text { be labeled with such a disorder, but need factual information (Hagerty et al., 2010). }\end{array}$ \\
\hline Sleep & $\begin{array}{l}\text { This module focuses on injuries and stress can interfere with sleep. Users identify strategies that can help them obtain } \\
\text { adequate rest such as: going to bed at a regular time each night; refraining from exercise late in the evening since exercise } \\
\text { can be physically activating, thus interfering with sleep; or not using alcohol for sleep. }\end{array}$ \\
\hline Problem solving & $\begin{array}{l}\text { In this module, users practice the steps in solving a problem by going through an example of a gunshot wound to the leg. } \\
\text { Then they identify a specific problem of their own, and practice brainstorming possible solutions, narrowing their options, } \\
\text { and identifying advantages, disadvantages, and barriers to potential solutions (Dixon, 2000; D'Zurilla \& Goldfried, 1971; } \\
\text { Nezu, 2004; Nezu, Nezu, \& Perri, 1989). }\end{array}$ \\
\hline Belonging & $\begin{array}{l}\text { Increasing sense of belonging has significant effects on the psychological and social well-being of an individual (Hagerty \& } \\
\text { Williams, 1999; Hagerty, Williams, Coyne, \& Early, 1996; Williams et al., 2004). Therefore, users review strategies to } \\
\text { increase their sense of belonging. Topics include: belonging in the military; belonging and war injuries; strategies to } \\
\text { increase one's sense of belonging; reacting and coping with issues of belonging; and finding resources to help. }\end{array}$ \\
\hline Relationships & $\begin{array}{l}\text { This module deals with relationships under stress, communication, new relationships, and support systems. It focuses on } \\
\text { strategies to maintain healthy relationships (Fontana, Rosenheck, \& Horvath, 1997; Ganster \& Victor, 1988). }\end{array}$ \\
\hline Balance & $\begin{array}{l}\text { This module helps users find balance in their lives. It examines the competing demands of deployment, work, or recovery, and } \\
\text { the demands of family. The module provides strategies to assist them to learn how to balance competing and often } \\
\text { conflicting demands (Dixon \& Reid, 2000). }\end{array}$ \\
\hline
\end{tabular}

the military, deployment to or near a war zone, and length of time deployed. The questionnaire took about $4 \mathrm{~min}$ to complete.

\section{Patient Measures}

Patient's Evaluation Questionnaire. The single analog scale of the patients' perceived stress on a scale of 1 (no stress) to 10 (extreme stress) was measured before using Stress Gym and after completion of the Internet intervention. The analog scale is typically used to measure the intensity, strength, or magnitude of individuals' subjective feelings (Waltz, Strickland, \& Lenz, 2005). This type of a single measure of intensity has been used extensively in pain and general health (i.e., Cella \& Perry, 1986; Good et al. 2001; Wells, Burnam, Rogers, Hays, \& Camp, 1992). Reliability and concurrent validity have been shown in the previous version of Stress Gym for Navy service members (Williams et al., 2010).

The evaluation comprised a five-point, Likert-type scale (strongly agree to strongly disagree) of statements regarding patients' experience using Stress Gym. Examples are: "I like having the Virtual Log to record my thoughts and feelings, and track my progress" and "Stress Gym helped me to manage my stress and anger." The second section allowed patients to write comments on the Web-based intervention, what they liked, disliked, and recommendations for modifications. The final section included demographic information: gender, age, marital status, racial/ethnic background. The questionnaire also included background questions, such as type of injuries from combat, rank in the military, years in the military, deployment to a war zone, and length of time deployed. The questionnaire took about $4 \mathrm{~min}$ to complete.

Short Screening Scale for Post-Traumatic Stress Disorder (PTSD). This short seven-item instrument screens for PTSD symptoms. The seven items are scored by summing the positive responses (yes or no) with scores ranging from 0 to 7 . Several examples of items include: (a) Did you avoid being reminded of this experience by staying away from certain places, people, or activities? and (b) Did you begin to feel more isolated or distant from other people? The screening scale was tested on 237 Veterans Administration patients in 
primary care. The scale had a test-retest reliability of 0.84 $(p<.001)$. Validity measures using quality indices for cut scores of 4 (6.2), 5 (6.6), and 6 (6.6) were nearly identical, indicating that these scores maximized both sensitivity and specificity (Kimerling et al., 2006). The distinct advantage of the instruments was its short administration, and high sensitivity and specificity (Sugg \& Inui, 1992).

Personal Health Questionnaire (PHQ-2). The PHQ-2 is a very short measure used to assess the percent of patients screened positive for depression symptoms. The instrument asks two criteria, one of which must be met to be diagnosed with major depressive disorder according to the Diagnostic and Statistical Manual of Mental Disorders (4th ed., rev.; American Psychiatric Association, 2000), including depressed mood or loss of interest in usual activities. The instrument is scored on the two items from 0 to 3, ranging from "not at all" to "nearly every day," with the total score ranging from 0 to 6 (Kroenke, Spitzer, \& Williams, 2003). The probability of any depressive disorder with a score of 1 is $15.4 \%$ to $36.9 \%$, and a score of 6 is $78.6 \%$ to $92.9 \%$ (Thibault \& Prasaad-Steiner (2004). A PHQ-2 score of $\geq 3$ had a sensitivity of $83 \%$ and a specificity of $92 \%$ for major depression. Likelihood ratio and receiver operator characteristic analysis identified a score of 3 as the optimal cut point for screening purposes. The construct and criterion validities of the PHQ-2 make it a useful measure for depression screening (Kroenke et al., 2003).

\section{Procedures}

Onsite research associates at each MTF were trained to recruit nurses caring for combat-wounded patients and work with the staff to identify combat-wounded patients that met inclusion criteria. The researchers had a laminated copy of the Stress Gym home page to point out aspects of it, including the Evaluation button to access the anonymous Evaluation Questionnaire while recruiting participants. They were also given a compact disc with selected pages of the Web site. Participants were also given a login card with instructions to access a secure Web site that contained all the informational and interactive Web pages for Stress Gym. To protect the program from use by nonstudy participants, research associates in each military MTF gave participants an invitation code to access the Consent Form. The nurses and combat-wounded patients were informed that they would participate as volunteers, and were not required to complete Stress Gym. The program was completely anonymous. After they read the Consent Form on the Internet program, participants indicated if they were willing to participant by selecting yes or no. If they indicated no, then they were thanked for their consideration and the program ended.If they clicked yes, then the program took them to a page to create a unique identification code only known by them that allowed access to Stress Gym at a later point. There was no way to identify the subject. No names or e-mail addresses were part of their participation in the study. The study was approved for protection of human subjects by University of Michigan Institutional Review Board (IRB), the National Naval Medical Center, Bethesda, IRB, and for the Federal Wide Assurance Addendum by the Navy Bureau of Medicine and Surgery, Wilford Hall/Brooke Army Medical Center (BAMC), and the Walter Reed Army Medical Center (WRAMC) IRB.

Nurses who indicated that they did not care for combatwounded patients were the only exclusion criteria for nurse participation. Exclusion criteria for patients included if the patient was unable to complete tasks or had physical injuries that prevented participation in the study such as brain injury that exceeded a mild concussion or diminished capacity that interfered with reading and completing the Stress Gym modules. Exclusion criteria were evaluated by study staff if they believed that the patient did not have the ability to complete the Internet program and Evaluation Questionnaire.

\section{Results}

\section{Nurses Who Cared for Combat-Wounded Patients}

An evaluation of Stress Gym was provided by 124 nurses who completed the Evaluation Questionnaire at the completion of their review of the Web site. On average, the nurses logged on to Stress Gym for $36.1 \mathrm{~min}(S D=41.1 \mathrm{~min})$. There were no significant differences at the amount of time logged on in the four sites that participated $(F(3,120)=1.15, p=$ not significant $[\mathrm{NS}]$ ).

There were 22 evaluation items in the Questionnaire and 19 items had greater than $80 \%$ marks of "strongly agree" or "agree," with median ratings on all items as 4 (Table 3 ). There were no significant differences in the evaluations from the four sites using chi-square $(p=N S)$ and totaling the 22 items to create a total evaluation score using ANOVA $(F[3,114]=$ $1.32, p=\mathrm{NS}$ ). In addition, there were no significant differences in evaluations scored based on the three military services (Air Force, Army, and Navy) $(F[2,113]=.047, p=\mathrm{NS}$ ); males versus females $(t[122]=0.24, p=\mathrm{NS})$; ethnic/racial background $(F[4,112]=1.39, p=\mathrm{NS})$; education level (some college to doctorate $)(F[4,111]=0.16, p=\mathrm{NS})$; and deployed or not deployed before participating in the study $(t[122]=$ $0.25, p=$ NS). There were also no significant differences by military service, sex, ethnic/racial background, education level, and deployment in the six categories of the Evaluation Questionnaire, comprising Ease of Use, Understanding, Content, Format, Motivation, and Intent to Use the Intervention. The correlation matrices of the subscales of the Evaluation Questionnaire were all strong significant correlations ranging from $r=.74$ to $r=.84$.

The number of activity modules, such as Stress and Emotion, and Problem Solving, completed by the nurses had 
Table 3. Stress Gym for Combat-Wounded Patients: Nurse Evaluations $(n=124)$

\begin{tabular}{|c|c|c|c|c|c|c|}
\hline Evaluation Items & $\begin{array}{l}S D \\
\%(n)\end{array}$ & $\begin{array}{l}\mathrm{D} \\
\%(n)\end{array}$ & $\begin{array}{l}N \\
\%(n)\end{array}$ & $\begin{array}{l}\text { A } \\
\%(n)\end{array}$ & $\begin{array}{l}\text { SA } \\
\%(n)\end{array}$ & $\begin{array}{l}\text { Mean } \\
(S D)\end{array}$ \\
\hline \multicolumn{7}{|l|}{ Ease of use } \\
\hline $\begin{array}{l}\text { I like that Stress Gym is on the Internet, always available whenever patients need } \\
\text { it. }\end{array}$ & $0.8(1)$ & $0.0(0)$ & $5.7(7)$ & $39.3(48)$ & $54.2(66)$ & $4.5(0.68)$ \\
\hline $\begin{array}{l}\text { I like that Stress Gym lets patients work at their own pace and on any strategy } \\
\text { they wish. }\end{array}$ & $0.8(1)$ & $0.0(0)$ & $7.3(9)$ & $39.0(48)$ & $52.9(65)$ & $4.4(0.70)$ \\
\hline Stress Gym is easy to navigate. & $0.8(1)$ & $2.4(3)$ & $8.1(10)$ & $52.8(65)$ & $35.9(44)$ & $4.2(0.76)$ \\
\hline Stress Gym is organized so that it makes sense to me. & $0.8(1)$ & $3.2(4)$ & $9.7(12)$ & $54.8(68)$ & $31.5(39)$ & $4.1(0.78)$ \\
\hline \multicolumn{7}{|l|}{ Understanding } \\
\hline I think that patients can learn at least one strategy to help them manage stress. & $0.8(1)$ & $0.8(1)$ & $6.5(8)$ & $52.0(64)$ & $39.9(49)$ & $4.3(0.70)$ \\
\hline Stress Gym can help patients to understand how they respond to stress. & $0.8(1)$ & $2.5(3)$ & $9.0(11)$ & $53.3(65)$ & $34.4(42)$ & $4.2(0.76)$ \\
\hline Stress Gym can help patients to understand how they respond to anger. & $0.8(1)$ & $2.4(3)$ & $9.8(12)$ & $54.5(67)$ & $32.5(40)$ & $4.2(0.76)$ \\
\hline \multicolumn{7}{|l|}{ Content } \\
\hline Stress Gym covers topics important to combat-wounded patients. & $0.8(1)$ & $0.8(1)$ & $6.5(8)$ & $42.7(53)$ & $49.2(61)$ & $4.4(.72)$ \\
\hline Stress Gym can be helpful to military personnel injured in combat. & $0.8(1)$ & $0.8(1)$ & $14.9(18)$ & $45.5(55)$ & $38.0(46)$ & $4.2(0.78)$ \\
\hline $\begin{array}{l}\text { Stress Gym covers topics important to nurses who care for combat-wounded } \\
\text { patients. }\end{array}$ & $0.8(1)$ & $0.8(1)$ & $13.0(16)$ & $44.7(55)$ & $40.7(50)$ & $4.2(0.77)$ \\
\hline Stress Gym can help me to provide care to my combat-wounded patients. & $0.8(1)$ & $2.4(3)$ & $13.8(17)$ & $56.9(70)$ & $26.1(32)$ & $4.0(0.76)$ \\
\hline \multicolumn{7}{|l|}{ Format } \\
\hline I like that Stress Gym is private. & $0.8(1)$ & $0.0(0)$ & $9.7(12)$ & $39.5(49)$ & $50.0(62)$ & $4.4(0.73)$ \\
\hline I like that Stress Gym lets patients print visual reminders. & $0.8(1)$ & $0.0(0)$ & $9.1(11)$ & $40.5(49)$ & $49.6(60)$ & $4.4(0.72)$ \\
\hline $\begin{array}{l}\text { I like that the Virtual Log lets patients record their thoughts and feelings, and } \\
\text { track their progress. }\end{array}$ & $0.8(1)$ & $0.0(0)$ & $9.8(12)$ & $36.6(45)$ & $52.8(65)$ & $4.4(0.73)$ \\
\hline I like that Stress Gym is interactive, not just a lecture. & $0.8(1)$ & $1.6(2)$ & $7.3(9)$ & $41.9(52)$ & $48.4(60)$ & $4.4(0.76)$ \\
\hline I like the animations in Stress Gym. & $1.6(2)$ & $6.5(8)$ & $20.2(25)$ & $48.3(60)$ & $23.4(29)$ & $3.9(0.91)$ \\
\hline \multicolumn{7}{|l|}{ Motivation } \\
\hline $\begin{array}{l}\text { I like that Stress Gym gives patients directions to seek professional help if they } \\
\text { need it. }\end{array}$ & $0.8(1)$ & $0.8(1)$ & $6.6(8)$ & $47.5(58)$ & $44.3(54)$ & $4.3(0.71)$ \\
\hline Stress Gym is fun even though it's serious work. & $1.7(2)$ & $8.3(10)$ & $16.7(20)$ & $50.0(60)$ & $23.3(28)$ & $3.9(0.93)$ \\
\hline The first page of Stress Gym is interesting and gets the attention of patients. & $1.6(2)$ & $4.1(5)$ & $23.6(29)$ & $54.4(67)$ & $16.3(20)$ & $3.8(0.82)$ \\
\hline \multicolumn{7}{|l|}{ Intent to use the intervention } \\
\hline $\begin{array}{l}\text { I would like to see Stress Gym available to all combat-wounded patients and the } \\
\text { nurses who care for them. }\end{array}$ & $0.8(1)$ & $0.8(1)$ & $13.8(17)$ & $44.7(55)$ & $39.9(49)$ & $4.2(0.77)$ \\
\hline I would recommend Stress Gym to combat-wounded patients. & $0.8(1)$ & $4.1(5)$ & $9.8(12)$ & $51.2(63)$ & $34.1(42)$ & $4.1(0.81)$ \\
\hline $\begin{array}{l}\text { Stress Gym could help friends or family members to understand what patients } \\
\text { experience. }\end{array}$ & $0.8(1)$ & $3.3(4)$ & $12.4(15)$ & $50.4(61)$ & $33.1(40)$ & $4.1(0.81)$ \\
\hline
\end{tabular}

SD, strongly disagree; $D$, disagree; N, neutral; A, agree; SA, strongly agree.

a mean 2.0 modules $(S D=1.7)$. However, all the nurses reviewed some of the submodules within a module. The first module, Stress and Emotion, was reviewed and completed by nearly $80 \%$ of the nurses. See Table 4 for the frequency and percentages of the modules reviewed. There were no significant differences in the number of modules completed by the nurses at the four MTFs $(F[3,67]=2.42, p=\mathrm{NS})$. A multiple linear regression of years of experience, age, sex, nursing specialty, and years in the military did not predict the evaluation of Stress Gym $(F[5,82]=0.20, p=$ NS). Nearly one third of nurses $(29.8 \% ; n=37)$ recommended that Stress Gym be used for their patients during hospitalization, and nearly two thirds of nurses $(63.7 \% ; n=79)$ recommended its use during convalescence/outpatient treatment.

Participants were asked to comment on what they liked most in Stress Gym, what they disliked, and what they would change to make Stress Gym better. Out of the 124 nurses who participated, 109 made comments. The most frequent comment made about what they liked was the interactivity of the modules within Stress Gym. As an example, one nurse wrote:

Table 4. Review of Modules in Stress Gym by the Nurses $(n=124)$

\begin{tabular}{lll}
\hline Modules & $\begin{array}{l}\text { Reviewed } \\
\text { Entire Module } \\
\%(\boldsymbol{n})\end{array}$ & $\begin{array}{l}\text { Reviewed } \\
\text { Sub-Modules } \\
\boldsymbol{\%}(\boldsymbol{n})\end{array}$ \\
\hline Stress and emotion & $79.0(98)$ & $21.0(26)$ \\
Reacting to stress & $65.3(81)$ & $34.7(43)$ \\
Anger & $59.7(74)$ & $40.3(50)$ \\
Changing your thinking & $53.2(66)$ & $46.8(58)$ \\
Sleep & $49.2(61)$ & $50.8(63)$ \\
Balance & $45.2(56)$ & $54.8(68)$ \\
Problem solving & $40.3(50)$ & $59.7(74)$ \\
Belonging & $0(0)$ & $57.3(71)$ \\
\hline
\end{tabular}


The interactive quality and ability to look at different areas of the site without limitations; being able to self-pace and choose items that are more meaningful at any point in a person's recovery will increase the likelihood that they will come back if they can look at the topics that are important to them at any given time without forcing topics on them that may be too uncomfortable at a specific time. It is also a good way for casualties to be able to evaluate themselves without someone hanging over their shoulder judging them about their feelings and needs.

Another nurse stated: "I like that it is incredibly visual and interactive. At first I thought that it was simply a click and read lecture, but the visuals and animations were very effective." Many of the nurses commented that they liked specific modules and features such as PTSD Jeopardy, Ants and Boot animation, stress log, and the program's ability to maintain a virtual log of patients' interactions and journaling features in privacy.

The themes of comments that were most frequently mentioned by the nurses were they disliked "nothing" or that the program was "too long." However, as one nurse indicated, "I think the modules were a good length, but I could see that when patients are in the hospital and not entirely focused they might find Stress Gym modules to be long. Patients might need some encouragement to work on a little bit each day." Some nurses disliked the clip art and preferred to see actual pictures "of nurses and active duty personnel. The animation takes away from the military flair of the site."

The most common theme for recommendations to make Stress Gym better was "Nothing-A great program!” Another common theme was, "Just more real photos of our wounded warriors and our nurses at the bedside with these patients. Also more shots of our warriors in every day settings back in the States like walking down the street with their family." Four nurses recommended a section on caregivers. As one nurse emphasized:

There is an incredible amount of stress and difficulty for both the medical staff and the family members who provide care for casualties. A lot of this information would be good for them to see, to give a little perspective, but a section especially for the caregivers as well would make this a totally awesome sight all around. Allowing caregivers to see what tools are there for their patients or loved ones with a little reminder that they are hurting and stress out as well would benefit everyone. I have been taking care of casualties in one form or another for $12+$ years now and I am seeing the stress reaction in myself change as I am affected by the attitudes and issues of both the casualties I care for and their family members.

\section{Combat-Wounded Patients}

The patients had all been deployed once during the injuries, and two described their injuries as "shrapnel wounds from an $82 \mathrm{~mm}$ mortar round" and "PTSD." They were injured between 2004 and 2010. All of the median scores on each of the Evaluation Questionnaire items were 4.0, which means that the patients agreed with the Ease of Use, Understanding, Content, Format, Motivation, and Intent to Use the Intervention.

On a scale from 1 to 10 indicating increase perceived stress levels, four of the patients rated their stress level from 4 to 7 . Only three patients provided their perceived stress levels at the completion of Stress Gym; two patients indicated a decrease by 2 points ( 5 to $3 ; 7$ to 5 ) and one patient indicated no change ( 4 to 4 ). There were too few patients to conduct analysis for their evaluations of Stress Gym to predict their scores of PTSD symptoms and depression symptoms.

The patients' responses on the Short Screening Scale for PTSD produced a mean of $5.50(S D=1.0)$ and a median of 6 , with scores ranging from 4 to 6 indicating positive screening for symptoms of PTSD (Kimerling et al., 2006). The PHQ-2 (Kroenke et al., 2003) screening of depression had a mean of $3.80(S D=2.59)$ and a median of 4 , with scores ranging from 0 to 6 indicating depressive symptoms that could meet criteria for major depressive disorder.

Three of the five patients wrote comments regarding what they liked most: "pace"; "ways on how to deal with stress"; and "it is easy to understand." What they disliked were: "computer work"; "N/A, was overall very helpful"; and "Overall it's good, some content is hard to do due to TBI issues." One recommended adding more video, and another stated, "I think it is good."

\section{Discussion}

Most of the demographic background characteristics were similar in comparing the four MTFs. However, there were significant differences in sex and racial/ethnic background. For reasons unknown, more males participated in the study from WRAMC and BAMC than the other two MTFs. Yet there were no significant differences in the evaluation of Stress Gym based on sex. Similarly, the racial/ethnic background of WRAMC is significantly different than at the other three MTFs. Again, however, there were no significant differences among the evaluations based on racial/ethnic background among the study sites.

The average time logged on provides evidence that the Web site is reasonable for participants examining the modules they select. The length of time is similar to that reported in Williams et al. (2010). There were no differences in the amount of time logged on based on the demographics. 
The comments of nurses on their likes, dislikes, and recommendations were also encouraging. One of our goals was to use interactivity to make the Web site different and more useful to participants than many existing Web sites. Positive comments by nurses on the interactivity of the Web site were consistent with the design. The comment that they disliked "nothing" also provided encouragement. Comments that the Web site was too long may have been due to our not emphasizing enough that Stress Gym was not designed for one-time use. Rather, it was designed to be used as often as needed, and the modules visited by users could vary over time according to a user's individual needs. In part because of this, Stress Gym was capable of saving user responses for later reflection and updating. Nonetheless, their comments indicate that we need to be clearer when we specify these capabilities of the program.

The suggestion of the nurses that we use more photographs of "real" soldiers and of nurses at a soldier's bedside is noteworthy. Because of our limited research budget, we attempted to draw upon Web sites that had available military-themed photographs. Our challenge was to find photos that were congruent with content. In the future, a budget to help develop the Web site could include contracting with a photographer that would fit the content specifically within modules of the Web site, thus increasing congruency.

The recommendation to include a section on caregivers' stress and/or burden has merit. In a previous research study (Hagerty, Williams, Bingham, \& Richard, 2010), nurses identified the importance of the involvement of the family as well as the burden that family members placed on nurses who care for their loved ones. By addressing the stress associated with injuries and behavioral outcomes, the Web site has the potential to help families understand what their injured family member is going through. This holds the potential of helping family to know better how to provide support to the patient.

Nurses were asked when Stress Gym could best be used by patients. Nearly two thirds suggested when patients were convalescing. This was our intent when we designed the program. The disappointing, small number of patients reflected the complexity in timing when and how the Web site is introduced to patients. When patients are hospitalized, they are often managing acute pain of injuries, or are in a confused state because of an improvised explosive device injury and/or traumatic brain injury. Therefore, only a select group of patients may be appropriate to use Stress Gym during inpatient hospitalization. As outpatients, they may be overwhelmed with appointments, procedures, wound care, rehabilitation, and related activities. So, inviting patients to participate in a research study may not be an ideal time either. Therefore, the need to make Stress Gym a part of the treatment protocol in conjunction with usual care may be warranted to make the intervention available to them when they are ready to use the information and tools are built into the program. In addition, Stress Gym may be best used by family members and caregivers, who often accompany the wounded service members, but may be hesitant to ask for help as they may perceive themselves as needing to "stay strong" for the injured family member.

Despite the few number of patients who participated, their scores on the questionnaire were encouraging because their evaluations were similar to those of the nurses who provided care to combat-wounded patients. However, despite advances in technology and medical treatments that increase the survival rates of patients with even severe physical injuries, their evaluations suggest that we should still be concerned because of their higher scores for perceived stress, depression, and PTSD. This suggests the importance of providing not only for their physical care, but also for the unseen wounds to their brain and mental health. It is possible that for them the emotional fallout of war remains undertreated.

A significant strength of Stress Gym is that it enables all military personnel, including officers, to learn about and get help with such problems as stress, anger, anxiety, depression and PTSD symptoms, and being anonymous and in private.

\section{Implications for Nursing Practice}

Overall, the results on the 22-item evaluation questionnaire by the nurses were encouraging. Participants reported that the Web site was easy to navigate and understandable, with content and format that motivated them to use the intervention. It is encouraging that, unlike other interventions, Stress Gym does not seem to suffer from a lack of content that is engaging and relevant (Christensen et al., 2002; Prescott, 2001). There were no statistically significant chi-square differences in the evaluation of Stress Gym based upon sex, rank, occupational specialization, race/ethnic background, or whether or not participants had been deployed to or near a war zone. These findings are similar to those of Williams et al. (2010), which suggested that whether it is used for military personnel generally or specifically for combat-wounded veterans, Stress Gym maintains its utility. This suggests that Stress Gym is a versatile tool that can help nurses address the psychosocial needs of their patients by encouraging its use and including it in treatment protocols.

\section{Acknowledgments}

This paper was supported in part by the TriService Nursing Research Program, Uniformed Services University of the Health Sciences, and Elsie Andresen Research Fund at University of Michigan; however, the information or content and conclusions do not necessarily represent the official position or policy of, nor should any official endorsement be inferred by, the TriService Nursing Research Program, Uniformed Ser- 
vices University of the Health Sciences, the Department of Defense, or the U.S. Government.

\section{References}

American Psychiatric Association. (2000). Diagnostic and statistical manual of mental disorders (4th ed., rev.). Washington, DC: Author.

Beck, A. T., Rush, A. J., Shaw, B. F., \& Emery, G. (1979). Cognitive therapy of depression. New York: Guilford Press.

Cella, D. F., \& Perry, S. W. (1986). Reliability and concurrent validity of three visual-analogue mood scales. Psychological Reports, 59(2, Pt. 2), 827-833.

Christensen, H., Griffiths, K. M., \& Korten, A. (2002). Web-based cognitive behavior therapy: Analysis of site usage and changes in depression and anxiety scores. Journal of Medical Internet Research, 4(1), e3.

Clarke, G., Reid, E., Eubanks, D., O’Connor, E., DeBar, L., Kelleher, C., ... Nunley, S. (2002). Overcoming depression on the internet (ODIN): A randomized controlled trial of an Internet depression skills intervention program. Journal of Medical Internet Research, 4(3), e14. doi:102196/jmir.4.3.e14

Dixon, W. A. (2000). Problem-solving appraisal and depression: Evidence for a recovery model. Journal of Counseling \& Development, 78, 87-91.

Dixon, W. A., \& Reid, J. K. (2000). Positive life events as a moderator of stress-related depressive symptoms. Journal of Counseling \& Development, 78, 343-347.

D’Zurilla, T. J., \& Goldfried, M. R. (1971). Problem solving and behavior modification. Journal of Abnormal Psychology, 78, 107-126.

Flatley-Brennan, P. (1998). Computer network home care demonstration: A randomized trial in persons living with AIDS. Computers in Biology and Medicine, 28, 489-508.

Flood, J. (2002). Read all about it: Online learning facing $80 \%$ attrition rates. Turkish Online Journal of Distance Education, 3(2). Retrieved May 21, 2012, from http://tojde.anadolu.edu.tr/tojde6/articles/jim2.htm

Fontana, A., Rosenheck, R., \& Horvath, T. (1997). Social support and psychopathology in the war zone. Journal of Nervous and Mental Disorders, 185, 675-681.

Ganster, D. C., \& Victor, B. (1988). The impact of social support on mental and physical health. British Journal of Medical Psychology, 61, 17-36.

Good, M., Stiller, C., Zauszniewski, J. A., Anderson, G. C., Stanton-Hicks, M., \& Grass, J. A. (2001). Sensation and distress of pain scales: Reliability, validity, and sensitivity. Journal of Nursing Measurement, 9(3), 219-238.

Hagerty, B. K., \& Williams, R. A. (1999). The effects of sense of belonging, social support, conflict, and loneliness on depression. Nursing Research, 48(4), 215-219.

Hagerty, B. M., Williams, R. A., Bingham, M., \& Richard, M. (2010). Military nurses and combat-wounded patients: A qualitative analysis of psychosocial care. Perspectives in
Psychiatric Care, 47, 84-92. doi:10.1111/j.1744-6163.2010.00275.x

Hagerty, B. M. K., Williams, R. A., Coyne, J. C., \& Early, M. R. (1996). Sense of belonging and indicators of psychological and social functioning. Archives of Psychiatric Nursing, 10(4), 235-244.

Kelly, A. M., Uddin, L. Q., Biswal, B. B., Castelanos, F. X., \& Milham, M. P. (2008). Competition between functional brain networks mediates behavioral variability. Neuroimage, 39, 527-537.

Kimerling, R., Ouimette, P., Prins, A., Nisco, P., Lawler, C., Cronkite, R., \& Moos, R. H. (2006). Utility of a short screening scale for DSM-IV PTSD in primary care. Journal of General Internal Medicine, 21(1), 65-67. doi:10.1111/j.1525-1497.2005.00292.x

Kroenke, K., Spitzer, R. L., \& Williams, J. B. W. (2003). The Patient Health Questionnaire-2: Validity of a two-item depression screener. Medical Care, 41, 1284-1292. Retrieved from http://www.ncbi.nlm.nih.gov/pmc/articles/PMC1495268/ pdf/jgi_01114.pdf

Lazarus, R. S., \& Folkman, S. (1984). Stress, coping, and adaptation. New York: Springer.

Lieberman, M., Golant, M., Giese-Davis, J., Winzlenberg, A., Benjamin, H., Humphreys, K., . . . Spiegel, D. (2003).

Electronic support groups for breast carcinoma. Cancer, 97(4), 920-925. doi:10.1002/cncr.11145

Nezu, A. M. (2004). Problem solving and behavior therapy. Behavioral Therapy, 35, 1-33.

Nezu, A. M., Nezu, C. M., \& Perri, M. G. (1989). Problem-solving therapy for depression: Theory, research, and clinical guidelines. New York: Wiley.

Prescott, M. (2001). Digital game-based learning. New York: McGraw-Hill.

Sugg, N. K., \& Inui, T. (1992). Primary care physicians’ response to domestic violence: Opening Pandora's box. Journal of the American Medical Association, 267, 3157-3160.

Thibault, J. M., \& Prasaad-Steiner, R. W. (2004). Efficient identification of adults with depression and dementia. American Family Physician, 70, 1101-1110.

Waltz, C. F., Strickland, O. L., \& Lenz, E. R. (2005). Measurement in nursing and health research (3rd ed., pp. 146-148). New York: Springer.

Wells, K. B., Burnam, M. A., Rogers, W., Hays, R., \& Camp, P. (1992). The course of depression in adult outpatients. Results from the Medical Outcomes Study. Archives of General Psychiatry, 49(10), 788-794.

Williams, R. A., Hagerty, B. M., Andrei, A. C., Yousha, S. M., Hirth, R. A., \& Hoyle, K. S. (2007). STARS: Strategies to assist navy recruits' success. Military Medicine, 172(9), 942-949.

Williams, R. A., Hagerty, B. M., Brasington, S., Clem, J., \& Williams, D. A. (2010). Stress Gym: Feasibility of deploying a Web-enhanced behavioral self-management program for stress in a military setting. Military Medicine, 175, 487-493. Retrieved from http://findarticles.com/p/articles/mi_qa3912/is_201007/ ai_n55066533 
Williams, R. A., Hagerty, B. M., Yousha, S. M., Horrocks, J., Hoyle, K. S., \& Liu, D. (2004). Psychosocial effects of the BOOT STRAP intervention in Navy recruits. Military Medicine, 169(10), 814-820.

Williams, R. A., Hagerty, B. M., Yousha, S. M., Hoyle, K. S., \& Oe, H. (2002). Factors associated with depression in navy recruits.
Journal of Clinical Psychology, 58(4), 323-337. doi:10.1002/jclp.1146

Winzelberg, A., Classen, C., Alpers, G., Roberts, H., Koopman, C., Adams, R., . . Taylor, B. (2003). Evaluation of an Internet support group for women with primary breast cancer. Cancer, 97(5), 1164-1173. doi:10.1002/cncr.11174 